\title{
Effects of Pulse Current on Dynamic Recrystallization Behavior of GH4169 Superalloy
}

\author{
Yang Liu ${ }^{1}$, Lei Wang ${ }^{1, *}$, Hui-Hong Liu ${ }^{1}$, Xu-Dong $\mathrm{Lu}^{2}$ and Bei-Jiang Zhang ${ }^{2}$ \\ ${ }^{1}$ Key Laboratory for Anisotropy and Texture of Materials, Northeastern University, Shenyang 110819, P. R. China \\ ${ }^{2}$ Department of High-temperature Materials, Central Iron and Steel Research Institute, Beijing 100081, P. R. China
}

\begin{abstract}
The pulse current was applied on the GH4169 alloy during tensile tests at $800^{\circ} \mathrm{C}$. The effects of pulse current on the deformation behavior and recrystallization of the alloy were investigated, and the mechanisms were also discussed. The results show that the deformation resistance decreases and the elongation increases significantly by applying the pulse current during tensile tests of the alloy. And the effects of pulse current on the strength and plasticity of the alloy are more remarkable as the pulse current energy increases. It is found that the deformation resistance of the alloy can be decreased since the dislocation motion can be promoted during the tensile testing. The initial temperature of recrystallization can be reduced by the electric effect of the pulse current and the dynamic recrystallization nucleation is promoted. Therefore, the dynamic recrystallization would occur at lower temperature than that of the alloy without pulse current. That is the main reason for the decreasing of deformation resistance and the increasing of plastic deformation ability of GH4169 alloy under the pulse current. [doi:10.2320/matertrans.MBW201102]
\end{abstract}

(Received November 25, 2011; Accepted May 16, 2012; Published June 27, 2012)

Keywords: GH4169 superalloy, pulse current, electroplastic, dynamic recrystallization

\section{Introduction}

Superalloy is a key material for manufacturing the modern aerospace engines. With the rapid development of the aerospace industry, the turbine inlet temperature continuously increases $^{1)}$ and the service conditions of the key components are more severe. Accordingly, the excellent heat-resistance property of the alloy is required for use in the gas turbine ${ }^{2)}$ and the thermal strength of the alloy must meet the present requirement. But when the thermal strength of the alloy increases, the deformation resistance increases and the plasticity decreases, which leads to hard hot working. ${ }^{3,4)}$ At the same time, the high recrystallization temperature, slow recrystallization rate and complicated microstructure of the alloy ${ }^{5)}$ result in the rise of the lower limit of the temperature range of hot working deformation, which makes the temperature ranges of hot working deformation narrower. ${ }^{6}$ It becomes the main reason for the hardly hot working of the alloy, which will no doubt limit the development and application of the wrought superalloy.

Considering from the energy perspective, the energy of different forms applied on the alloy during hot working would resolve the natural contradiction between the high thermal strength and difficult hot working deformation of the alloy. Studies on the metallurgical process of the metallic materials under the pulse current ${ }^{7,8)}$ have been done, and it is found that the electroplastic effect is one of the outstanding features of the process. The plastic deformation resistance can be reduced and the plasticity can be improved by the electron-wind-force by applying current pulses in deformation process of the material, which is termed electroplastic effect. ${ }^{9)}$ There are progressive results in many fields based on the pulse current technique, which is applied on the wrought metal materials during its plastic forming, such as the electroplastic drawing and the electroplastic rolling. ${ }^{10-12)}$ For this reason, the applying of pulse current to the tensile

*Corresponding author, E-mail: wanglei@mail.neu.edu.cn deformation of the wrought superalloy is very useful for resolving the problems of the high deformation resistance and enlarging the hot working temperature range for the superalloy.

In the present study, the pulse current treatment is applied on the GH4169 alloy during tensile testing at $800^{\circ} \mathrm{C}$. The effects of the pulse current parameters on the deformation behavior and dynamic recrystallization of the alloy were investigated; the mechanism of the effect of the electric effect on the recrystallization behavior of the alloy was also discussed.

\section{Experimental Procedures}

The GH4169 superalloy was prepared by double vacuum melted (vacuum induction melted and vacuum arc remelted) and then hot rolled into $\Phi 35 \mathrm{~mm}$ bar. The chemical compositions of the alloy is shown in Table 1. After solution treatment at $1060^{\circ} \mathrm{C}$ for $1 \mathrm{~h}$ with water cooling, the alloy was machined into a plate type tensile specimen, with a gauge section of $1.2 \mathrm{~mm} \times 10 \mathrm{~mm} \times 25 \mathrm{~mm}$.

The tensile testing was carried out on MTS 810 material testing system at $800^{\circ} \mathrm{C}$. The schematic diagram of the specimen clamping device for tensile test is shown in Fig. 1. The electrode of HPC-5 type pulse power was connected with the specimen by a special tensile insulation clamping. And the SiC laminated composite was used as the insulation material between the clamping and specimens. The high temperature testing chamber of MTS 810 system was used for temperature compensation and the compensation param-

Table 1 Chemical compositions of GH4169 alloy (mass\%).

\begin{tabular}{ccccccc}
\hline $\mathrm{C}$ & $\mathrm{Si}$ & $\mathrm{Mn}$ & $\mathrm{P}$ & $\mathrm{S}$ & $\mathrm{Cr}$ & $\mathrm{Mo}$ \\
\hline 0.031 & 0.094 & 0.025 & 0.010 & 0.002 & 18.250 & 3.065 \\
\hline $\mathrm{Al}$ & $\mathrm{Ti}$ & $\mathrm{Nb}$ & $\mathrm{B}$ & $\mathrm{Fe}$ & $\mathrm{Cu}$ & $\mathrm{Ni}$ \\
\hline 0.620 & 1.020 & 5.230 & 0.005 & 19.145 & 0.300 & $\mathrm{Bal}$. \\
\hline
\end{tabular}




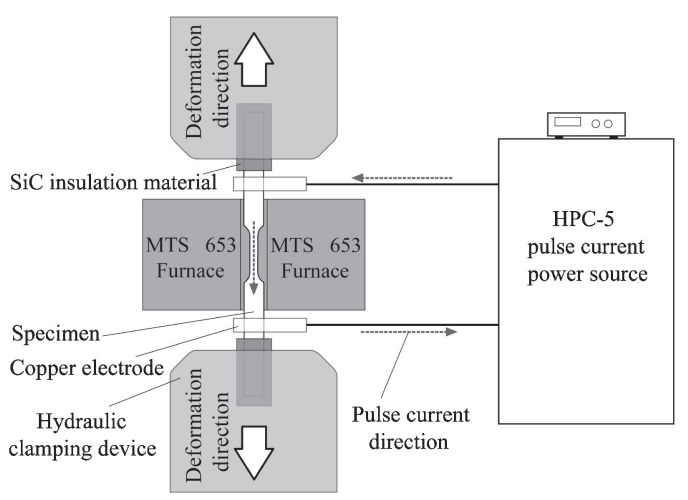

Fig. 1 Schematic diagram of the specimen clamping device for tensile test of GH4169 alloy under the pulse current.

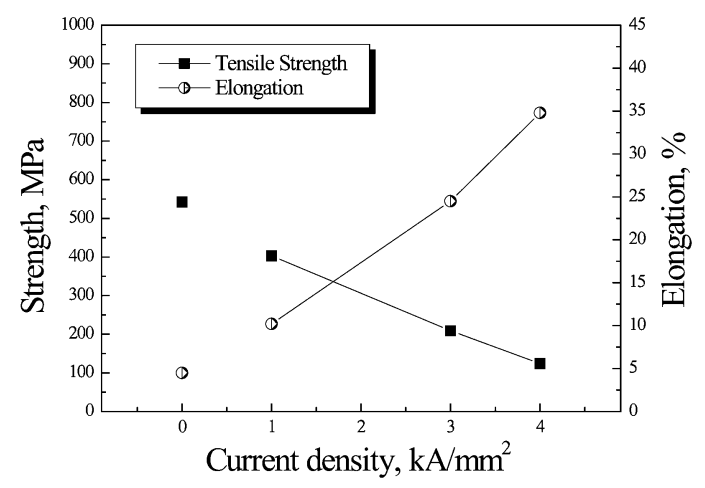

Fig. 2 Variations of the tensile property of $\mathrm{GH} 4169$ alloy at $800^{\circ} \mathrm{C}$ with the current density.

eters were carefully controlled to keep a temperature accuracy of $\pm 0.5^{\circ} \mathrm{C}$. Both the fine thermocouple and RAYTEC 3I-LRL3 infrared temperature measuring meter were used for accurate measurement and real time control of the specimen temperature.

The microstructure, tensile facture morphology and the microstructure near the fracture surface of the specimen were examined by an optical microscope (OLYMPUS GX71), a laser scanning confocal microscope (OLYMPUS LEXT $3100)$ and a field emission scanning electron microscope (JEOL 7001).

\section{Results and Discussion}

\subsection{Deformation behavior}

Figure 2 shows the variations of the tensile property of the alloy tested at $800^{\circ} \mathrm{C}$ with the pulse current density. It is seen that the tensile strength of the alloy significantly decreases under the pulse current and it decreases $25.9 \%$ at the current density of $1 \mathrm{kA} / \mathrm{mm}^{2}$ and $77.8 \%$ at $4 \mathrm{kA} / \mathrm{mm}^{2}$, compared with that of the alloy without the pulse current, respectively. And the elongation of the alloy significantly increases as the current density increases and it increases $145.0 \%$ at the current density of $1 \mathrm{kA} / \mathrm{mm}^{2}$ and $750.2 \%$ at $4 \mathrm{kA} / \mathrm{mm}^{2}$, compared with that of the alloy without the pulse current, respectively.

Figure 3 shows the stress-strain curves of GH4169 alloy tested at $800^{\circ} \mathrm{C}$ with different current density. It can be noticed that there is a remarkable change in the curves as the

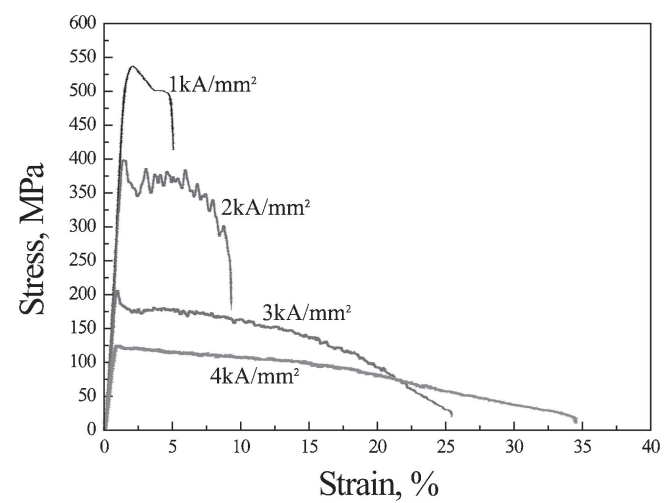

Fig. 3 Stress-strain curves of GH4169 alloy after tensile test at $800^{\circ} \mathrm{C}$ with different current densities.

\begin{tabular}{|c|c|c|}
\hline $\begin{array}{c}\text { Without the } \\
\text { pulse current }\end{array}$ & $2 \mathrm{kA} / \mathrm{mm}^{2}$ & $3 \mathrm{kA} / \mathrm{mm}^{2}$ \\
\hline & & \\
\hline & & \\
\hline & & \\
\hline & & \\
& & \\
\hline
\end{tabular}

Fig. 4 Fracture morphologies of GH4169 alloy after tensile test at $800^{\circ} \mathrm{C}$ with different current densities.

current density increases. The deformation resistance of the elastic deformation range has no obvious change under the pulse current compared with that of the alloy without the pulse current. However, both the elastic limit and the deformation resistance of the plastic deformation range decreased significantly, thus the plastic deformation ability increases. The strength decreases more than $20 \%$ and the plasticity increases more than $100 \%$ of the alloy with the pulse current density of $1 \mathrm{kA} / \mathrm{mm}^{2}$, compared with that of the alloy without the pulse current. When the current density increases to $4 \mathrm{kA} / \mathrm{mm}^{2}$, the strength decreases more than $75 \%$ and the plasticity increases $700 \%$ of the alloy.

Figure 4 shows the tensile fracture morphology of GH4169 alloy tested with different current densities. The alloy without the pulse current shows characteristics of typical intergranular fracture and multi-secondary cracks along grain boundary on the fracture surface. While the number of the secondary cracks along grain boundary decreases and the number of dimples increases in the alloy with the pulse current density of $2 \mathrm{kA} / \mathrm{mm}^{2}$, which indicates that the alloy exhibits typical ductile fracture characteristics. When the current density increases to $3 \mathrm{kA} / \mathrm{mm}^{2}$, the size of dimples decreases and its number increases further. At the same time, there is an obvious decrease in the number of the cavities formed by breakage of the primary carbides. It suggests that the fracture mechanism of the alloy changed with applying the pulse current, even if at the same deformation temperature, so that the plastic deformation ability of alloy has been markedly improved. 
(a)

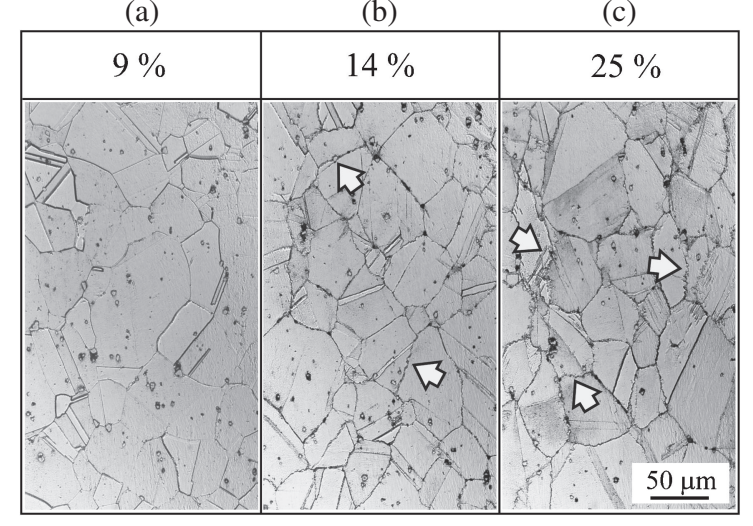

Fig. 5 Microstructure of GH4169 alloy tensile tested at $800^{\circ} \mathrm{C}$ with different deforming ratios under the pulse current with the condition of $4 \mathrm{kA} / \mathrm{mm}^{2}, 10 \mathrm{~Hz}$ and $30 \mu \mathrm{s}$.

\subsection{Contribution of electric effect}

It has been reported that there is an extra force acting on the moving dislocations induced by drift electrons named $F_{\mathrm{e}}$ by applying pulse current on metallic materials. ${ }^{13)}$

$$
F_{\mathrm{e}}=\frac{\boldsymbol{b}}{4}\left[\frac{V_{\mathrm{e}}}{V_{\mathrm{d}}}-1\right] \frac{V_{\mathrm{d}}}{V} \frac{\partial n_{0}}{\partial \mu} \Delta^{2}
$$

where, $\boldsymbol{b}$ is the Burgers vector. $V_{\mathrm{e}}$ and $V_{\mathrm{d}}$ are the moving rate of electron and dislocation, respectively. $V$ is the electron rate on Fermi surface. $n_{0}$ is the concentration of free electrons. $\mu$ is chemical potential, and $\Delta$ is constant. When $V_{\mathrm{e}}>V_{\mathrm{d}}, F_{\mathrm{e}}$ becomes the positive value, and the dislocation motion will be accelerated. And the acceleration of the dislocation motion will be faster when the current density is higher, and thus the increasing of plasticity of metallic materials will be more remarkable. The drift electrons would help dislocations to overcome resistance from obstacles and lattice resistance, and result in the significantly decreasing of plastic deformation resistance and much improving of plasticity during deformation of GH4169 alloy with employing the high density electric pulse current.

However, the promoting effect of the simple electronwind-force on the dislocation motion couldn't have such a remarkable result at the constant temperature of $800^{\circ} \mathrm{C}$. There must be another effect of pulse current, which would decrease the deformation resistance and increase the plasticity of GH4169 alloy.

Figure 5 shows the microstructure of GH4169 alloy tensile tested with different deforming ratios at $800^{\circ} \mathrm{C}$ under the pulse current with the condition of $4 \mathrm{kA} / \mathrm{mm}^{2}, 10 \mathrm{~Hz}$ and $30 \mu \mathrm{s}$. It is evident that the appearance of the elongated grains is not obvious and the initial grain boundary is smoother at the deforming ratio of $9 \%$. When the deforming ratio is increased to $14 \%$, obvious plastic deformation characteristic of elongated grain, deforming twins and deforming bands can be observed. It is noticed that the bulging of some initial grain boundaries, as marked by arrows shown in Fig. 5(b), which indicates the dynamic recrystallization has occurred in the alloy under this deformation state. As the deforming ratio continues to increase, the characteristics such as the grain elongation along the tensile direction, the deforming twins and the deformation bands become more obvious as marked

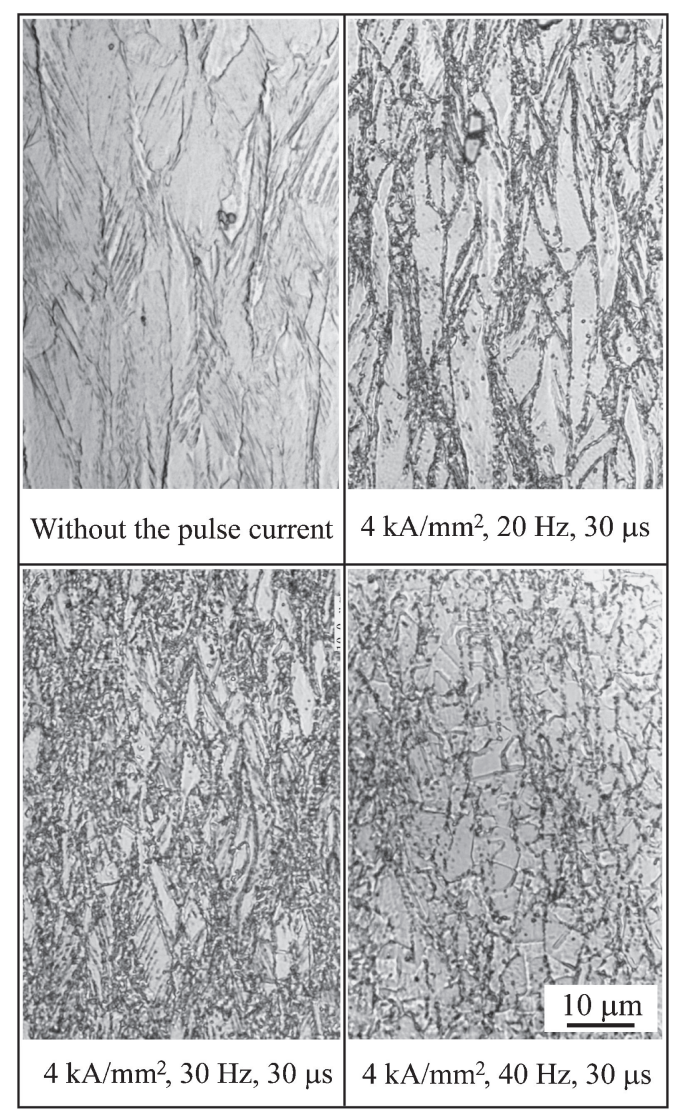

Fig. 6 Microstructures of GH4169 alloy without the pulse current and with the pulse current at $650^{\circ} \mathrm{C}$ for $0.5 \mathrm{~h}$ after cold rolling.

by arrows shown in Fig. 5(c). More and more grain boundary bulging and serrated grain boundares appear with the increasing of the deforming ratio, indicating the degree of dynamic recrystallization increases.

\subsection{Effect of pulse current on recrystallization behavior 3.3.1 Initial temperature of recrystallization}

In order to clear the effect of the non-thermal effects on the recrystallization behavior of GH4169 alloy, the temperature compensation and nitrogen cooling have been employed in the present study to ensure the same temperature under different pulse current conditions. Figure 6 shows the microstructure of the GH4169 alloy without pulse current at $650^{\circ} \mathrm{C}$ for $0.5 \mathrm{~h}$ and under the pulse current for $0.5 \mathrm{~h}$ after cold rolling with $54 \%$ reduction. It shows that the microstructure of the alloy is still the cold rolled microstructure at $650^{\circ} \mathrm{C}$ for $0.5 \mathrm{~h}$. While as for the alloy under the pulse current with the condition of $4 \mathrm{kA} / \mathrm{mm}^{2}, 20 \mathrm{~Hz}$ and $30 \mu \mathrm{s}$, which the specimen is also controlled to keep at $650^{\circ} \mathrm{C}$ for $0.5 \mathrm{~h}$, the recrystallization characteristics and the precipitation of $\delta$ phase at the original high angle grain boundary, the twin grain boundary and the deforming band can be found, although the microstructure is still cold rolling deformed microstructure. And as the pulse frequency increases, such tendency gradually increases. It can be seen that most of the deformed grains in the matrix had been swallowed by a great deal of fine and uniform recrystallization grains with the size of $2 \mu \mathrm{m}$ when the pulse frequency increases to $40 \mathrm{~Hz}$. 
Table 2 Initial temperatures of recrystallization of GH4169 alloy without the pulse current and with pulse current after cold rolled with 54\% reduction.

\begin{tabular}{|c|c|c|c|c|}
\hline & $\begin{array}{c}\text { Density } \\
\left(\mathrm{kA} / \mathrm{mm}^{2}\right)\end{array}$ & $\begin{array}{l}\text { Frequency } \\
\quad(\mathrm{Hz})\end{array}$ & $\begin{array}{c}\text { Duration } \\
(\mu \mathrm{s})\end{array}$ & $\begin{array}{c}\text { Temperature } \\
\left({ }^{\circ} \mathrm{C}\right)\end{array}$ \\
\hline $\begin{array}{l}\text { Without the } \\
\text { pulse current }\end{array}$ & - & - & - & 862 \\
\hline \multirow{10}{*}{ Pulse current } & 3 & \multirow{2}{*}{40} & \multirow{2}{*}{30} & 748 \\
\hline & 4 & & & 665 \\
\hline & \multirow{4}{*}{4} & 10 & \multirow{4}{*}{30} & 801 \\
\hline & & 20 & & 753 \\
\hline & & 30 & & 692 \\
\hline & & 40 & & 665 \\
\hline & \multirow{4}{*}{4} & \multirow{4}{*}{40} & 15 & 727 \\
\hline & & & 20 & 713 \\
\hline & & & 25 & 696 \\
\hline & & & 30 & 665 \\
\hline
\end{tabular}

Based on the microstructure observation of the alloy with the different pulse current treatment, the volume fraction of recrystallization was measured and the initial temperature of recrystallization was determined. Table 2 shows the effect of pulse current condition on the initial temperature of recrystallization of the alloy after cold rolling with 54\% reduction. It is clear that the initial temperature of recrystallization of the alloy with the pulse current is obviously decreased, compared with that of the alloy without pulse current. And the decreasing degree becomes larger with the increasing of current density, frequency and pulse duration.

\subsubsection{Recrystallization activation energy}

The cold rolled alloys were treated with and without pulse current under the conditions of different temperature and time, respectively. The isothermal recrystallization curves were measured and the recrystallization activation energy of the alloy was obtained, as shown in Table 3. It indicates that the recrystallization activation energy of the alloy decreases with the increasing of the pulse current energy. When the pulse current under the condition of $4 \mathrm{kA} / \mathrm{mm}^{2}, 20 \mathrm{~Hz}$ and $30 \mu \mathrm{s}$, the recrystallization activation energy becomes $342.71 \mathrm{~kJ} / \mathrm{mol}$, which it decreases $40 \%$ compared with that of $577.19 \mathrm{~kJ} / \mathrm{mol}$ of the alloy without pulse current.

Under the effect of pulse current, a strong impacting force of high-rate drift electrons on atoms causes the generation of the Joule heat. It has been recognized that in metallic materials, the dissipation of electronic excitation into heat is very fast and the rate of the temperature rising can arrive at $10^{6 \circ} \mathrm{C} \cdot \mathrm{s}^{-1}$ order under the single current pulse. ${ }^{14)}$ Such highrate heating will generate nonsynchronous change of the temperature rising and the thermal expansion, while the thermal expansion falls behind the temperature rising. Therefore, a transient thermal compressive stress can be formed. The maximum stress can be expressed as: ${ }^{15)}$

$$
\sigma_{\max }=E \alpha \Delta T
$$

where $E$ is Young's modulus, $\alpha$ is the thermal expansion coefficient. A large amount of supersaturation point defects
Table 3 Effect of pulse current on recrystallization activation energy of the GH4169 alloy.

\begin{tabular}{ccc}
\hline $\begin{array}{c}\text { Without the } \\
\text { pulse current }\end{array}$ & $\begin{array}{c}\text { Pulse current } \\
3 \mathrm{kA} / \mathrm{mm}^{2}, 10 \mathrm{~Hz}, 30 \mu \mathrm{s}\end{array}$ & $\begin{array}{c}\text { Pulse current } \\
4 \mathrm{kA} / \mathrm{mm}^{2}, 20 \mathrm{~Hz}, 30 \mu \mathrm{s}\end{array}$ \\
\hline $577.19 \mathrm{~kJ} / \mathrm{mol}$ & $498.25 \mathrm{~kJ} / \mathrm{mol}$ & $342.71 \mathrm{~kJ} / \mathrm{mol}$ \\
\hline
\end{tabular}

will be formed by the transient thermal compressive stress, therefore the vacancy density in the alloy will be increased. The vacancy density in the alloy is proportional to the atomic transition frequency by vacancy diffusion mechanism. As a result, the increasing of transition frequency of atoms with the increasing of the vacancy density is beneficial to the diffusion. In other word, both of the activation energy for atomic transition and vacancy formation can be decreased by the pulse current, and at the same time the atom diffusion will be accelerated. Generally, the dislocation recovery occurs before recrystallization in an alloy, which enters into the subgrain boundary by dislocation slipping and climbing. The dislocation climb process controlled by the atomic diffusion process is much slower than the dislocation slipping process. As a result, the decreasing of the activation energy for atomic diffusion causes the decreasing of the activation energy of recrystallization. That is an important reason for the decreasing activation energy of recrystallization of the alloy with the pulse current.

With the applying of the pulse current during the tensile deformation of alloy, both the initial temperature and the apparent activation energy of the recrystallization can be decreased. Therefore, the deforming resistance of the alloy could be decreased and the hot working temperature range could be expanded with applying of the pulse current, which maybe one way for solving the problem of hard hot working of the wrought superalloy.

As a result, it can be summarized as that the electroplastic effect caused by the electron-wind-force and the promoting effect of pulse current on the recrystallization are the two important reasons for the significant improvement in the plastic deformation ability of GH4169 alloy.

\section{Conclusions}

(1) Under the pulse current, the deforming resistance of GH4169 alloy decreases and the elongation increases significantly during tensile testing at $800^{\circ} \mathrm{C}$. And this effect increases with the increasing of current pulse energy. Since the dislocation motion can be promoted by the electroplastic effect of the pulse current during the tensile deformation, the deformation resistance of the alloy can be decreased.

(2) Under the pulse current with the condition of 4 $\mathrm{kA} / \mathrm{mm}^{2}, 20 \mathrm{~Hz}$ and $30 \mu \mathrm{s}$, the recrystallization activation energy of GH4169 alloy is down to $342.71 \mathrm{~kJ} / \mathrm{mol}$, which is about $40 \%$ compared with that of the alloy without pulse current.

(3) The initial temperature of recrystallization can be reduced by the electric effect of the pulse current and the dynamic recrystallization nucleation is promoted. Therefore, the dynamic recrystallization would occur at 
lower temperature than that of the alloy without pulse current. That is the main reason for the decreasing of deforming resistance and the increasing of plasticity of GH4169 alloy with the pulse current.

\section{Acknowledgments}

This research was supported by National Basic Research (973) Program of China (No. 2010CB631203, 2011CB610506), National Natural Science Foundation of China (No. 51001021, 51171039) and Fundamental Research Funds for the Central Universities of China (No. 110410004).

\section{REFERENCES}

1) S. L. Soo, R. Hood, D. K. Aspinwall, W. E. Voice and C. Sage: CIRP Ann. Manuf. Technol. 60 (2011) 89-92.

2) R. Sharghi-Moshtaghin and S. Asgari: J. Mater. Process. Technol. 147 (2004) 343-350.
3) J. M. Zhang, Z. Y. Gao, J. Y. Zhuang and Z. Y. Zhong: J. Mater. Process. Technol. 88 (1999) 244-250.

4) J. L. Qu, J. H. Du, Q. Deng, J. Y. Zhuang and X. D. Lu: Mater. Sci. Technol. (China) 16 (2008) 121-124.

5) B. J. Zhang, G. P. Zhao, G. H. Xu and D. Feng: Acta Metal. Sin. (China) 41 (2005) 99-106.

6) B. J. Zhang, G. P. Zhao, L. Y. Jiao, G. H. Xu, H. Y. Qin and D. Feng: Acta Metal. Sin. (China) 41 (2005) 351-356.

7) H. Conrad: Mater. Sci. Eng. A 322 (2002) 100-107.

8) Z. H. Xu, G. Y. Tang, S. Q. Tian, F. Ding and H. Y. Tian: J. Mater. Process. Technol. 182 (2007) 128-133.

9) H. Conrad: Mater. Sci. Eng. A 287 (2000) 276-287.

10) G. Y. Tang, J. Zhang, M. X. Zheng, J. Zhang, W. Fang and Q. Li: Mater. Sci. Eng. A 281 (2000) 263-267.

11) H. Conrad, N. Karam, S. Mannan and A. F. Sprecher: Scr. Metall. 22 (1988) 235-238.

12) Z. Y. Liu, X. T. Deng and Y. Z. Wang: Chinese J. Mater. Res. (China) 15 (2001) 358-366.

13) O. A. Troitskii: Mater. Sci. Eng. A 75 (1985) 37-50.

14) Y. Z. Zhou, R. S. Qin, S. H. Xiao, G. H. He and B. L. Zhou: J. Mater. Res. 15 (2000) 1056-1061.

15) D. W. Tang, B. L. Zhou, H. Cao and G. H. He: J. Appl. Phys. 73 (1993) 3749-3752. 